\title{
Alectinib for Miliary Lung Metastasis in ALK-Positive Lung Adenocarcinoma
}

\author{
Hironori Satoh' \\ Yusuke Okuma (1) \\ Jumpei Kashima ${ }^{2}$ \\ Aya Konnno-Yamamoto' \\ Yasushi Yatabe ${ }^{2}$ \\ Yuichiro Ohe (D) \\ 'Department of Thoracic Oncology, \\ National Cancer Center Hospital, Tokyo, \\ Japan; ${ }^{2}$ Department of Pathology, \\ National Cancer Center Hospital, Tokyo, \\ Japan
}

Correspondence: Yusuke Okuma Department of Thoracic Oncology, National Cancer Center Hospital, 5-I-I Tsukiji, Chuo, Tokyo, 105-0045, Japan

Tel +8I-3-3542-25II

Fax +8I-3-3542-38I5

Email yokuma@ncc.go.jp
Background: Miliary pulmonary metastasis characterized by tiny nodules is a rare metastatic pattern in advanced non-small cell lung cancer (NSCLC) and is usually seen in patients harboring an EGFR mutation, and amylase-producing lung cancer is highly uncommon and rarely reported in NSCLC patients who have an EGFR mutation.

Case: A 32-year-old Japanese female was found to have miliary pulmonary nodules throughout both lung fields on a chest x-ray examination during an annual health checkup. Further examination by computed tomography (CT) revealed diffuse, bilateral, miliary nodules. Blood tests showed no increased tumor marker levels, but there was a significantly increased serum amylase level. A diagnosis of $A L K$-rearranged adenocarcinoma was made based on the results of a mediastinal lymph node biopsy obtained by endobronchial ultrasound-guided transbronchial needle aspiration (EBUS-TBNA). Treatment with alectinib resulted in rapid regression of the CT shadows and a reduction in the patient's serum amylase level.

Conclusion: We have reported a case of $A L K$-rearranged NSCLC with a miliary pulmonary metastasis pattern that was sensitive to alectinib and in which the serum amylase level decreased in response to treatment with alectinib. Young patients with miliary pulmonary metastasis should be checked for all driver mutations.

Keywords: alectinib, $A L K$ rearrangement, non-small-cell lung cancer, miliary pulmonary metastasis

\section{Introduction}

Lung cancer is the leading cause of cancer-related deaths worldwide. Anaplastic lymphoma kinase $(A L K)$ gene rearrangement is one of the major genetic alterations in non-small cell lung cancer (NSCLC) characterized by the young, never- or previous light smokers. Patients with ALK rearrangement account for $8 \%$ of all NSCLC patients, following Kirsten rat sarcoma viral oncogene homolog (K-ras) and epidermal growth factor receptor $(E G F R)$ mutations. ${ }^{1}$ Treatment with ALK tyrosine kinase inhibitors (TKIs) has dramatically improved the survival of $A L K$ rearranged-NSCLC patients. $^{2}$

Miliary pulmonary metastasis by NSCLC, which occurs as a result of hematogenous dissemination, is known to be more common in patients harboring an $E G F R$ mutation. ${ }^{3}$ However, no cases of miliary pulmonary metastasis in $A L K$-rearranged NSCLC had ever been reported.

Here we report the case of an $A L K$-rearranged-NSCLC patient with miliary pulmonary metastasis in whom a significant response was achieved by treatment with alectinib, a second-generation ALK TKI. 


\section{Case Report}

A 32-year-old female non-smoker was found to have abnormal lung shadows on a chest x-ray during an annual check-up. A computed tomography (CT) scan at the previous hospital showed a small cavitary nodule in the left upper lobe and diffuse tiny nodules throughout both lungs. The serum tuberculosis-specific IFN- $\gamma$ test was negative, and tumor marker levels were not elevated. Transbronchial lung biopsy specimens obtained bronchoscopically showed suspected miliary metastasis by a lung cancer.

The patient had a slight cough and no history of respiratory disease, and her Eastern Cooperative Group Performances Status (ECOG-PS) was 0. Blood examinations demonstrated none of the significantly increased tumor markers levels (CEA 1.6 ng/mL, CYFRA 0.6 ng/mL, Pro GRP $54.5 \mathrm{pg} / \mathrm{mL}$ ), but her serum amylase levels were elevated (total amylase $584 \mathrm{IU} / \mathrm{L}$, pancreatic amylase $76 \mathrm{IU} / \mathrm{L}$ ).

A chest X-ray showed bilateral diffuse shadows at our hospital (Figure 1A). A CT scan revealed a $19 \mathrm{~mm}$ cavitary nodule in the left upper lobe and multiple small nodules with a random distribution throughout both lung fields, swollen mediastinal lymph nodes, and spinal metastasis (L4 and L5) (Figure 1B). No CT findings were detected in the salivary glands or pancreas. Magnetic resonance imaging (MRI) of the brain revealed multiple skull metastases but no evidence of brain metastasis (cT4aN2M1c, Stage IV). She underwent both transbronchial lung biopsy (TBLB) from the left upper lung and endobronchial ultrasound-guided trans-bronchial needle aspiration (EBUS TBNA) from the mediastinal lymph nodes. Hematoxylin and eosin (HE) staining revealed adenocarcinoma cells in the EBUS TBNA specimens (Figure 2A). In addition, ALK protein was confirmed to be positive by D5F3 ALK immunohistochemistry assay (Roche, Arizona, USA) of the TBLB samples (Figure 2A and C). The Oncomine ${ }^{\mathrm{TM}}$ Dx Target test (Thermo Fisher Scientific Inc., Waltham, MA, USA) showed no EGFR, ROS1 rearrangement, KRAS, BRAF, or other NSCLC driver mutations. The PD-L1 tumor proportion score (TPS of 10\%) was a low expression.

The patient was treated with alectinib (300 mg daily), and a CT scan after three months of the treatment showed a marked improvement in the miliary pulmonary
A

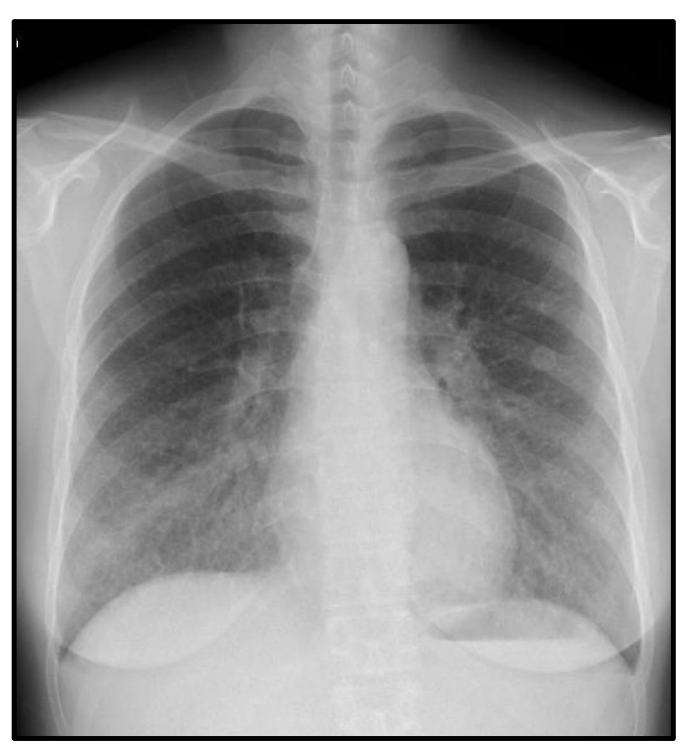

B

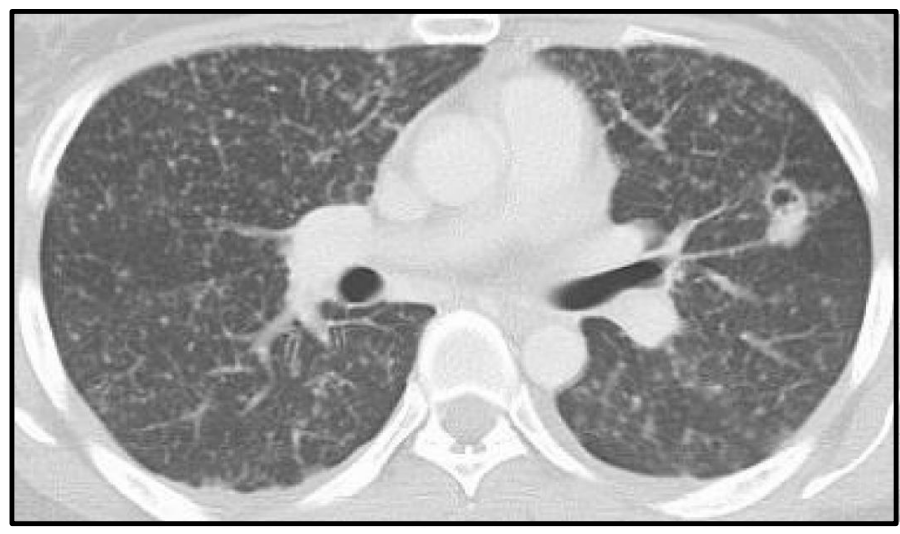

C

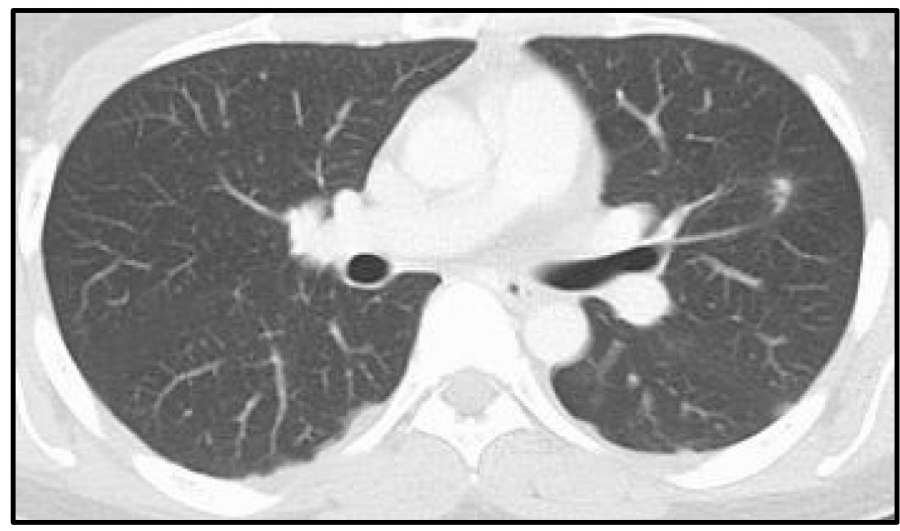

Figure I Chest X-ray and CT findings. (A) Chest X-ray at the first visit to our hospital revealed bilateral diffuse shadows and a small cavity in the left lung. (B) CT at the time of EBUS-TBNA showed small, discrete, rounded pulmonary nodules of uniform size diffusely distributed throughout both lung fields. A suspected cavitary primary lesion was identified in the left upper lobe. (C) Three months after the start of treatment with alectinib, the miliary metastasis shadows had decreased considerably. 

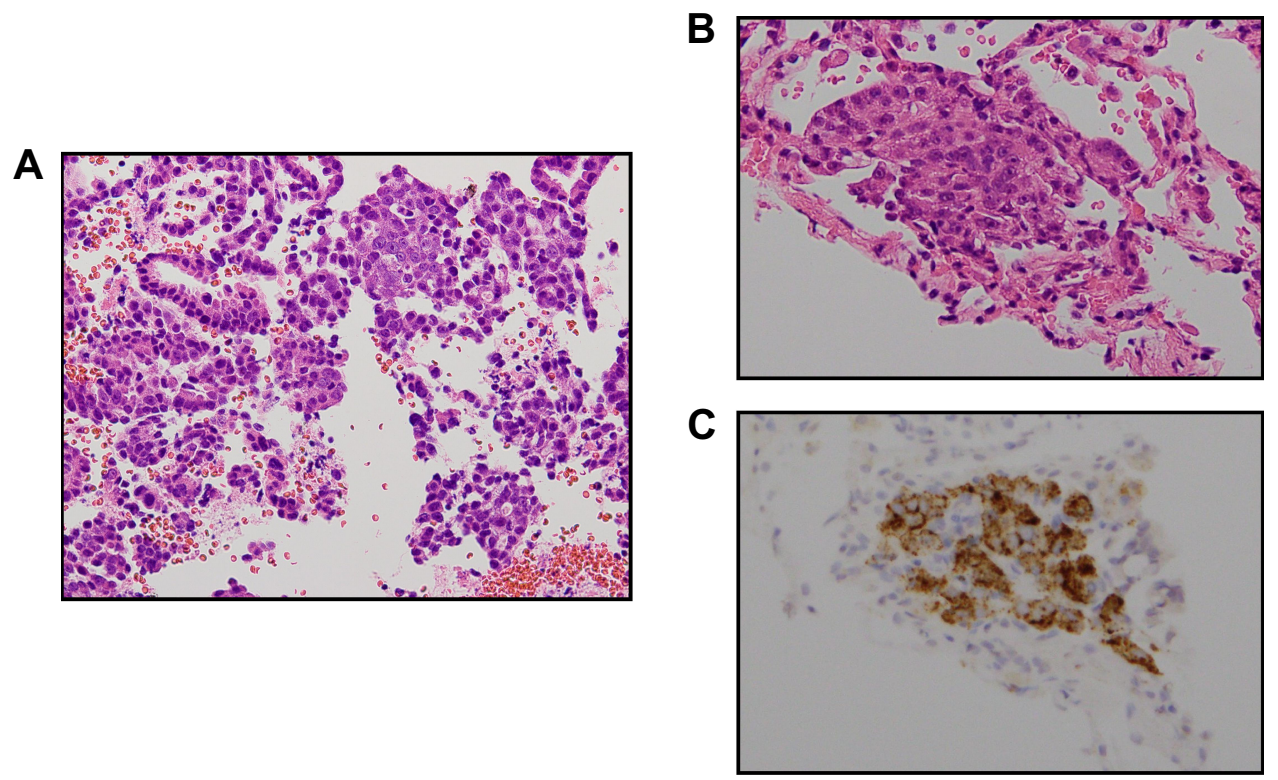

Figure 2 Pathological findings of biopsies obtained from the mediastinal lymph node and left upper lobe of the lung. (A) Cancer cells forming solid nests and acinar structure were observed in EBUS-TBNA specimens of the mediastinal lymph node. (B) Adenocarcinoma cells forming an ambiguous acinar structure were found in TBLB specimen of the cavity in the left upper lobe of the lung. (C) ALK protein was diffusely positive in the cytoplasm of the adenocarcinoma cells in the TBLB specimens.

metastasis in both lungs, and the patient's total serum amylase level had decreased (Figure 1C). A Grade 2 skin rash according to the Common Terminology Criteria for Adverse Events (CTCAE) version 5.0 appeared, but it rapidly responded to treatment with an antihistaminic agent. No severe adverse drug reactions have occurred at any time during treatment.

\section{Discussion}

We have reported a case of miliary pulmonary metastasis in a patient with $A L K$-rearranged NSCLC. Miliary pulmonary metastasis is defined as diffuse, random distribution of metastatic nodules throughout both lung fields. The metastatic lesions are profuse, tiny, discrete, rounded pulmonary nodules that measure less than $3 \mathrm{~mm}$ in their most significant dimension. ${ }^{4}$ Miliary pulmonary metastases harboring EGFR-mutation-positive NSCLC cells have frequently observed comparing to NSCLC without actionable driver mutations, ${ }^{3}$ and the metastases harboring $A L K$-rearranged NSCLC has not been reported until now. To our knowledge, there have been two case reports of miliary pulmonary metastasis in a patient with $A L K$-rearranged adenocarcinoma. However, the CT scan findings in those two cases did not meet the nodule size requirement in the above definition of miliary pulmonary metastasis., 5
EGFR mutations and $A L K$ rearrangements are two major driver mutations/alterations in NSCLC patients. Presentation with a miliary metastasis pattern has been associated with harboring an EGFR mutation, especially an exon 19 in-frame deletion. ${ }^{7}$ Patients with advanced NSCLC harboring an EGFR mutation who present with miliary pulmonary metastasis have had a substantially poorer outcome than patients with advanced NSCLC without miliary pulmonary metastasis. ${ }^{7,8}$

It has been hypothesized that there is a relationship between miliary pulmonary metastasis and bone metastasis. ${ }^{9}$ They assumed that firstly a primary lung cancer metastasizes to bone via the hematogenous route, secondly miliary metastasis arises from multiple tumor emboli from secondary bone metastasis foci. The detection of multiple bone metastases in our patient at the time of the initial diagnosis is consistent with this hypothesis.

Mycobacterium tuberculosis disseminates throughout the lungs via the blood. The attenuated immune system quickly leads to miliary tuberculosis and makes tiny granulomas in immunocompromised patients. ${ }^{10}$ The same as in tuberculosis, the downregulation of cellular immunity in patients with progressive lung cancer may increase susceptibility to miliary metastasis. Recently, cell-mediated immunity of lung cancer patients has been assessed by examining tumor-infiltrating lymphocytes (TILs) and PD-L1 expression by immunohistostaining. Since PD-L1 expression is correlated with the number 
of TILs, ${ }^{11}$ the low tumor proportion score (TPS) in our case suggests that the patient's T-cell immunity might have been severely attenuated. Meanwhile, it is well-known that cancer lymphangiopathy showed miliary nodules throughout the lung fields. The presence of multiple lymph node metastases in our patient might completely rule out the possibility of cancer lymphangiopathy, even though no lymphatic vessel invasion by cancer cells was detected in the histological samples.

A diagnosis of amylase-producing lung cancer was also considered in our patient because of the fluctuations in serum amylase levels that accompanied her disease progression and regression. Amylase-producing lung tumors were first reported in $1951,{ }^{12}$ and they are pathologically characterized by adenocarcinoma and the secretion of salivary-type amylase. Previous reports indicated that the increase in serum CEA was not observed in amylase-producing lung adenocarcinoma $^{13}$ at the point of diagnosis. Interestingly, the CEA levels gradually increased in spite of treatment, whereas the amylase levels decreased. In addition to our patient's normal CEA levels, the significant decrease in amylase when the tumor burden decreased after alectinib treatment, our case has a strong possibility of amylase-producing lung cancer. Our previous study in regard to miliary pulmonary metastasis in NSCLC patients with EGFR mutations found no increases in serum amylase levels, thereby indicating that amylase-producing tumors are exceptionally rare among patients with NSCLC harboring an EGFR mutation. To our knowledge, two case reports on amylase-producing tumors harboring an EGFR-mutations. ${ }^{13,14}$ Interestingly, amylase secretion by rat pancreatic cells is thought to be regulated by EGFR downstream signaling. ${ }^{15}$ The relationship between $A L K$-rearranged NSCLC and amylase-producing lung adenocarcinoma remains unclear. However, $A L K$ constitutive activity may lead to amylase expression under certain conditions because the same signal transduction pathway includes both EGFR and $A L K$.

CT imaging of miliary pulmonary metastasis nodules is known as the typical shadows not in cancer metastasis but in tuberculosis. In addition, because of our patient's characteristics including being a young female non-smoker and having normal serum tumor marker levels, we cannot promptly diagnose with lung cancer.

NSCLC patients with $A L K$ rearrangement, particularly female patients, tend to be younger than NSCLC patients with an EGFR mutation. Thus, the possibility of cancer metastasis should always be considered in the differential diagnosis of miliary pulmonary nodules and careful evaluation for $A L K$ rearrangement as well as $E G F R$ mutations should be performed, even if the patient is a young, female non-smoker with normal tumor marker levels.

In conclusion, we encountered a rare case of miliary pulmonary metastasis in a patient with $A L K$-rearranged NSCLC, and the patient responded dramatically to treatment with alectinib.

\section{Abbreviations}

ALK, anaplastic lymphoma kinase; CT, computed tomography; ECOG-PS, Eastern Cooperative Group Performances Status; EGFR, epidermal growth factor receptor; HE, hematoxylin and eosin; K-ras, Kirsten rat sarcoma viral oncogene homolog; MRI, magnetic resonance imaging; NSCLC, nonsmall cell lung cancer; TILs, tumor-infiltrating lymphocytes; TPS, tumor proportion score; TKI, tyrosine kinase inhibitor.

\section{Ethical Approval}

This case report was waivered by the Ethics Committee of National Cancer Center Hospital. The clinical information presented in this case report was obtained from the National Cancer Center Hospital's medical records.

\section{Informed Consent}

Written informed consent to publication of this case report was obtained from the patient.

\section{Acknowledgments}

We thank the International Medical Information Center for the English language review.

\section{Funding}

This research did not receive any specific grants from funding agencies in the public, commercial, or not-forprofit sectors.

\section{Disclosure}

Dr Yusuke Okuma reports grants, personal fees from Chugai, during the conduct of the study; grants from AbbVie, personal fees from AstraZeneca, personal fees from Eli Lilly, personal fees from from Taiho outside the submitted work. Dr Yuichiro Ohe reports grants, personal fees from Chugai, during the conduct of the study; grants, personal fees from AstraZeneca, grants from Amgen, grants, personal fees from Bristol-Myers Squibb, grants from Boehringer Ingelheim, grants from Celtrion, grants from Janssen, grants from Kyorin, grants from Kissei, grants from Ignyta, personal fees from Eli Lilly, grants, personal fees from MSD, grants from Nippon Kayaku, 
grants from Novartis, grants from ONO Pharmaceutical, grants from Taiho, grants from Takeda Pharmaceutical, grants from Pfizer, outside the submitted work.The authors report there are no other conflicts of interest.

\section{References}

1. Kris MG, Johnson BE, Berry LD, et al. Using multiplexed assays of oncogenic drivers in lung cancers to select targeted drugs. JAMA. 2014;311(19):1998-2006. doi:10.1001/jama.2014.3741

2. Solomon BJ, Kim DW, Wu YL, et al. Final overall survival analysis from a study comparing first-line crizotinib versus chemotherapy in ALK-mutation-positive non-small-cell lung cancer. J Clin Oncol. 2018;36(22):2251-2258. doi:10.1200/JCO.2017.77.4794

3. Togashi Y, Masago K, Kubo T, et al. Association of diffuse, random pulmonary metastases, including miliary metastases, with epidermal growth factor receptor mutations in lung adenocarcinoma. Cancer. 2011;117(4):819-825. doi:10.1002/cncr.25618

4. Hansell DM, Bankier AA, MacMahon H, McLoud TC, Muller NL, Remy J. Fleischner Society: glossary of terms for thoracic imaging. Radiology. 2008;246(3):697-722. doi:10.1148/radiol.2462070712

5. Khan D, Danjuma M, Saddique MU, Murshed KAH, Yassin MA. Adenocarcinoma of the lung mimicking miliary tuberculosis. Case Rep Oncol. 2020;13(1):139-144. doi:10.1159/000505685

6. Falk AT, Poudenx M, Otto J, Ghalloussi H, Barrire J. Adenocarcinoma of the lung with miliary brain and pulmonary metastases with echinoderm microtubule-associated protein like 4-anaplastic lymphoma kinase translocation treated with crizotinib: a case report. Lung Cancer. 2012;78(3):282-284. doi:10.1016/j.lungcan.2012.08.015

7. Kimmig L, Bueno J. Miliary nodules: not always tuberculosis. Ann Am Thorac Soc. 2017;14(12):1858-1860. doi:10.1513 AnnalsATS.201706-436CC
8. Okuma Y, Kashima J, Watanabe K, Homma S. Survival analysis and pathological features of advanced non-small cell lung cancer with miliary pulmonary metastases in patients harboring epidermal growth factor receptor mutations. J Cancer Res Clin Oncol. 2018;144 (8):1601-1611. doi:10.1007/s00432-018-2681-x.

9. Umeki S. Association of miliary lung metastases and bone metastases in bronchogenic carcinoma. Chest. 1993;104(3):948-950. doi:10.1378/chest.104.3.948

10. Sharma SK, Mohan A, Sharma A, Mitra DK. Miliary tuberculosis: new insights into an old disease. Lancet Infect Dis. 2005;5 (7):415-430. doi:10.1016/S1473-3099(05)70163-8

11. Oya Y, Kuroda H, Nakada T, Takahashi Y, Sakakura N, Hida T. Efficacy of immune checkpoint inhibitor monotherapy for advanced non-small-cell lung cancer with ALK rearrangement. Int J Mol Sci. 2020;21(7):2623. doi:10.3390/ijms21072623

12. Weiss MJ, Edmondson HA, Wertman M. Elevated serum amylase associated with bronchogenic carcinoma; report of case. Am J Clin Pathol. 1951;21(11):1057-1061. doi:10.1093/ajcp/21.11.1057

13. Minami S, Jokoji R, Yamamoto S, et al. Amylase-producing lung cancer with a positive epidermal growth factor receptor mutation treated with gefitinib: a case report. World J Oncol. 2014;5 (1):41-46. doi:10.14740/wjon778w

14. Ko HW, Tsai YH, Yu CT, Huang CY, Chen CH. Good response to gefitinib for lung adenocarcinoma with hyperamylasemia: a case report. Chang Gung Med J. 2008;31(6):606-611.

15. Stryjek-Kaminska D, Piiper A, Stein J, Caspary WF, Zeuzem S. Epidermal growth factor receptor signaling in rat pancreatic acinar cells. Pancreas. 1995;10(3):274-280. doi:10.1097/00006676199504000-00009
OncoTargets and Therapy

\section{Publish your work in this journal}

OncoTargets and Therapy is an international, peer-reviewed, open access journal focusing on the pathological basis of all cancers, potential targets for therapy and treatment protocols employed to improve the management of cancer patients. The journal also focuses on the impact of management programs and new therapeutic

Submit your manuscript here: https://www.dovepress.com/oncotargets-and-therapy-journa agents and protocols on patient perspectives such as quality of life, adherence and satisfaction. The manuscript management system is completely online and includes a very quick and fair peer-review system, which is all easy to use. Visit http://www.dovepress.com/ testimonials.php to read real quotes from published authors. 